EGU21-10042

EGU General Assembly 2021

(c) Author(s) 2021. This work is distributed under

the Creative Commons Attribution 4.0 License.

\title{
Cereal yield forecasting in Morocco using the CARAIB dynamic vegetation model driven by HadGEM2-AO projections
}

\author{
Iliass Loudiyi ${ }^{1}$, Ingrid Jacqemin ${ }^{2}$, Bernard Tychon ${ }^{2}$, Louis François ${ }^{2}$, Mouanis Lahlou ${ }^{3}$, Joost \\ Wellens $^{2}$, and Riad Balaghi ${ }^{4}$ \\ ${ }^{1}$ Institute of astrophysics and geophysics, University of Liège, Belgium (iliass.loudiyi@uliege.be) \\ ${ }^{2}$ Research unit: SPHERES, University of Liège, Belgium \\ ${ }^{3}$ The Agronomic and Veterinary Institute Hassan 2, Morocco \\ ${ }^{4}$ National Institute of Agronomic Research, Morocco
}

Food security, in Morocco as in many parts of the world, depends heavily on cereal production which fluctuates relying on weather conditions. In fact, Morocco has a production system for cereals which is dominated by rainfed. It is therefore necessary to further develop knowledge about climate change and strengthen forecasting systems for predicting the impacts of climate change.

Our research, funded by a bilateral project of Wallonie-Bruxelles International, aims to study the response of cereal production to climate change, using the dynamic vegetation model CARAIB (CARbon Assimilation In the Biosphere) developed within the Unit for Modelling of Climate and Biogeochemical Cycles (UMCCB) of the University of Liège. This spatial model includes crops and natural vegetation and may react dynamically to land use changes. Originally constructed to study vegetation dynamics and carbon cycle, it includes coupled hydrological, biogeochemical, biogeographical and fire modules. These modules respectively describe the exchange of water between the atmosphere, the soil and the vegetation, the photosynthetic production and the evolution of carbon stocks and fluxes in this vegetation-soil system. For crops, a specific module describes basic management parameters (sowing, harvest, rotation) and phenological phases.

The simulations are performed across all Morocco using different input data. The three main cereal crops simulated include soft wheat, durum wheat and barley, they are grown in all provinces and all agro-ecological zones. Regarding climatic inputs, we're using two sets of data: the first one is interpolated and bias-corrected fields from the climate model HadGEM2-AO for the historical period (1990-2005), in addition to three different Representative Concentration Pathway scenarios (RCP2.6, RCP4.5 and RCP8.5) from 2005 to 2100. The second one is high resolution (30 arc sec) gridded climate data derived from WorldClim combined with interpolated anomalies from CRU (Climatic Research Unit) over the historical period 1990 to 2018.

After obtaining preliminary results for the past period, and in order to improve the prediction using the field data which are the observed yields, we performed a sensitivity analysis. We used the One-at-a-time (OAT) approach by moving one input variable, keeping others at their baseline (nominal) values, then, returning the variable to its nominal value, then repeating for each of the 
other inputs in the same way. Sensitivity may then be measured by monitoring changes in the output, using linear regression. The inputs studied are the initial value of carbon pool, leaf $\mathrm{C} / \mathrm{N}$ ratio, water stress, sowing date, GDD harvest, stomatal conductance parameters, specific leaf area, and rooting depth. 